\title{
Relationship Between Solute Diffusion Coefficient and Electrical Conductivity Under Extremely Low Soil Water Conditions
}

\author{
Katori Miyasaka ${ }^{1}$ (D) Sho Shiozawa ${ }^{2}$
}

Received: 6 June 2021 / Accepted: 29 January 2022 / Published online: 2 March 2022

(c) The Author(s) 2022

\begin{abstract}
The relative diffusion coefficient $\left(D_{r}\right)$ of solutes in soils is directly proportional to the " $n$ th" power of the volumetric soil water content $(\theta)$, where $n$ is an empirical parameter, which normally ranges between 1 and 2 . The existence of a breakpoint $\left(\theta_{b r}\right)$ in the relationship between $\theta$ and $D_{r}$ has been demonstrated at low- $\theta$, in which the value of $n$ becomes approximately 4 when $\theta<\theta_{b r}$. The change in $n$ can be attributed to various mechanisms, including drastic changes in the geometrical distribution of pore liquid water caused by dehydration. However, as direct $D_{r}$ measurements require considerable time to render sufficient data at low- $\theta$, few studies have measured $D_{r}$ at $\theta<\theta_{b r}$, and the relationship between $D_{r}$ and $\theta$ at $\theta<\theta_{b r}$ remains unclear. In this study, we investigated if the indirect $D_{r}$ measurement method can be applied in the low- $\theta$ region of $\theta<\theta_{b r}$. An indirect method for measuring $D_{r}$ was employed to determine the soil electrical conductivity $\left(\mathrm{EC}_{\mathrm{s}}\right)$. Using dune sands in which the presence of $\theta_{b r}$ was confirmed, $D_{r}$ from high- to low- $\theta$ was calculated based on $\mathrm{EC}_{\mathrm{s}}$ measurements and compared with directly measured $D_{r}$. The relationships between $\theta$ and $D_{r}$ calculated based on $\mathrm{EC}_{\mathrm{s}}$ and using the transient state method were almost the same. $D_{r}$ could be calculated from $\mathrm{EC}_{\mathrm{s}}$ even at $\theta<\theta_{b r}$. The results confirmed that the indirect Dr measurement method can be applied for the low- $\theta$ region of $\theta<\theta_{b r}$.
\end{abstract}

Keywords Solute diffusion coefficient in soil · Relative diffusion coefficient of solute in soil · Soil electrical conductivity · Percolation model · Dune sand

\section{Introduction}

The solute diffusion coefficient in soil, $D_{p}$, is one of the important parameters for predicting salt and nutrient transfer and contaminant transport as well as for the use of contaminant remediation studies, risk assessments, and waste disposal management. $D_{p}$ is defined by Fick's first law, which states that the solute diffusion flux in soil is proportional to the macroscopic concentration gradient, while the proportionality coefficient is equal to the diffusion coefficient, as shown in Eq. (1) below.

Katori Miyasaka

miyasaka.katori@nihon-u.ac.jp

1 College of Bioresource Sciences, Nihon University, 1866

Kameino, Fujisawa-shi, Kanagawa 252-0880, Japan

2 Graduate School of Agricultural and Life Sciences, The University of Tokyo, 1-1-1 Yayoi, Bunkyo-ku, Tokyo 113-8657, Japan
$J=-\theta D_{p}(\theta) \frac{\partial C}{\partial x}$

where $J$ is the solute flux, $\theta$ is the volumetric water content, $C$ is the concentration of the solute in the soil solution, and $x$ is the distance. $D_{p}$ is expressed as follows:

$D_{p}(\theta)=\alpha \gamma \tau_{d}(\theta) D_{o}$

where $D_{o}$ is the solute diffusion coefficient in bulk water, $\alpha$ is a factor that accounts for the increase in drag caused by the higher viscosity of water closer to particle surfaces, $\gamma$ is a factor representing the electrostatic forces on charged diffusing substances, and $\tau_{d}(\theta)$ is the diffusive tortuosity factor (Olsen et al. 1965).

However, notably, some studies have used $D_{p}{ }^{*}$, which includes the effect of $\theta$ in the solute diffusion coefficient in soil. The relationship between $D_{p}$ and $D_{p}{ }^{*}$ can be expressed by the following equation:

$D_{p}^{*}=D_{p} / \theta$ 
The empirical relationship between the relative diffusion coefficient of solute in soil, $D_{r}\left(D_{r}=D_{p} / D_{o}\right)$, and $\theta$ can be represented as follows:

$D_{r}=k \theta^{n}$

where $k$ and $n$ are empirical parameters. The impedance factor, $f$, which is defined as the liquid phase impedance factor (Porter et al. 1960), is the same as $D_{r}$.

Several previous studies have reported that the value of $n$ at higher $\theta$ ranges approximately between 1 and 2 (Barraclough and Tinker 1981; Olsen et al. 1965; Olesen et al. 1996; Porter et al. 1960; So and Nye 1989). This experimental $n$ value range can be explained through physical tortuosity models, including a simple tortuosity (Papendick and Campbell 1981) or percolation model (Ewing and Horton 2003; Hunt and Ewing 2003), where factors $\alpha$ and $\gamma$ can be neglected (Olsen et al. 1965).

In contrast, only limited studies have measured $D_{r}$ at low $\theta$ (Hamamoto et al. 2009; Mehta et al. 1995; Miyasaka et al. 2014; Rowell et al. 1967; Tokunaga et al. 2017). Mehta et al. (1995) reported a breakpoint $\left(\theta_{b r}\right)$ in the relationship between $\theta$ and $D_{r}$ at low $\theta$ in single-grained soil (Shonai dune sand) or aggregated soil (Kanto loam). The breakpoints occur at around $D_{r}=0.1$ for both soils, and $\theta_{b r}$ values correspond to a matric potential value of $0.1 \mathrm{MPa}$ (Mehta et al. 1995). The value of $n$ is $\sim 1$ at $\theta \geq \theta_{b r}$, but it is $\sim 4$ at $\theta<\theta_{b r}$. Most of the soil solution at $\theta<\theta_{b r}$ would exist in electrically charged double layers on the surface of the solid particles. Therefore, molecular ion diffusion would be restricted in this solution compared with bulk solution. Thus, the value of $\gamma$ in Eq. (2), which is negligible at high $\theta$, can have an effect at low $\theta$.

Miyasaka et al. (2014) measured the diffusion coefficient of electrolyte solutes $\left(\mathrm{NaCl}\right.$ and $\left.\mathrm{CaCl}_{2}\right)$ in soil, which may be affected by soil surface charges, as well as non-electrolyte solutes (glycerin; $\mathrm{C}_{3} \mathrm{H}_{5}[\mathrm{OH}]_{3}$ ), which should not be affected by soil surface charges, over a wide range of water content conditions in Shonai dune sand and Kanto loam. These experiments demonstrated that the $D_{r}$ value for all the analyzed solutes was largely equal even at $\theta<\theta_{b r}$, indicating that the observed sharp decline in $D_{r}$ with low $\theta$ in the studied soils should not be attributed to the electric charge on the particle surface. Instead, Miyasaka et al. (2014) suggested that these sharp declines should be attributed to other mechanisms, such as pronounced changes in the geometrical distribution of pore liquid water due to dehydration. Therefore, the percolation model ( $n$ value in Eq. (4) ranges from 1 to 2) can be only applied at $\theta \geq \theta_{b r}$, where the pore water in the soil exhibits large-scale continuity, and not at $\theta<\theta_{b r}$, where the large-scale continuity in pore water disappears. The different model ( $n$ value in Eq. (4) is $\sim 4$ ) should be applied at low $\theta$ (Miyasaka et al. 2014; Yang et al. 2016).
Several studies have measured $D_{r}$ using a transient-state method, in which concentration profiles were measured in soil columns initially exhibiting step-shaped profiles (Mehta et al. 1995; Miyasaka et al. 2014; Robin et al. 1980; Rowell et al. 1967). However, maintaining appropriate boundary conditions for direct steady-state techniques poses several important challenges (Conca and Wright 1990). Furthermore, column rotation was required to prevent convective soil water flow caused by density differences in the soil solution (Mehta et al. 1995; Rowell et al. 1967). This rotation may have led to gravity-mediated soil water flow at high $\theta$ near saturation, thus causing transversal dispersion and an overestimation of the solute diffusion coefficient (Miyasaka et al. 2014). Additionally, the transient-state method requires an inordinate amount of time to render sufficient data at low $\theta$.

The most widely used indirect method is the measurement of soil electrical conductivity $\left(\mathrm{EC}_{\mathrm{b}}\right)$ (Abderrahmene et al. 2017; Bezzar and Ghomari 2013; Conca and Wright 1992; Garrouch et al. 2001; Mojid et al. 2007). This is a simple, rapid, and inexpensive method for $D_{r}$ detection. Using this method, $D_{r}$ can be estimated by measuring $\mathrm{EC}_{\mathrm{b}}$ using the Nernst-Einstein equation (Conca and Wright 1992). However, although some studies have measured $D_{r}$ in rocks at low $\theta$ using the indirect method (Conca and Wright 1992), very few studies have measured $D_{r}$ in soils at low $\theta$ where the percolation model cannot be adapted.

Here, the relationship between $D_{r}$ and $\theta$ was determined by measuring the electrical conductivity of Shonai dune sand over a wide range of soil moisture contents. The results were compared with the directly measured relationship between $D_{r}$ and $\theta$ by Miyasaka et al. (2014). We then examined the feasibility of deriving $D_{r}$ from $\mathrm{EC}_{\mathrm{b}}$ measurements at low soil $\theta$ wherein the percolation model cannot be applied.

\section{Materials and Methods}

\subsection{Relationship Between the Solute Diffusion Coefficient in Soil and the Soil Electrical Conductivity}

Although the liquid phases of soil particles have a complex structure, the $\mathrm{EC}_{\mathrm{b}}$ of any part of soil particles is inversely proportional to the path length of the ion and directly proportional to the cross-sectional area of the liquid phase (Rhoades et al. 1976). Therefore, $\mathrm{EC}_{\mathrm{b}}$ can be expressed by the following equation using the electrical conductivity of bulk soil solution, $\mathrm{EC}_{\mathrm{w}}$, and electrical conductivity of the surface layer of soil particles $\left(\mathrm{EC}_{\mathrm{s}}\right)$ :

$\mathrm{EC}_{\mathrm{b}}=\theta \mathrm{EC}_{\mathrm{w}} T(\theta)+\mathrm{EC}_{\mathrm{s}}$ 
where $T(\theta)$ is the transmission coefficient (Rhoades et al. 1976). $T(\theta)$ accounts for the tortuous nature of the current lines and any decreases in the mobility of ions near the solid-liquid interface (Rhoades et al. 1976).

$T(\theta)=\beta \tau_{e}(\theta)$

where $\tau_{e}(\theta)$ is the electrical tortuosity, and $\beta$ is a factor that accounts for decreases in the mobility of ions near the solid-liquid interface. At high $\theta, \beta$ in Eq. (6) can be ignored. Moreover, $\mathrm{EC}_{\mathrm{s}}$ can be ignored in soils that contain small amounts of clay (e.g., sandy soil). Therefore, at high $\theta, \mathrm{EC}_{\mathrm{b}}$ can be expressed as follows:

$\mathrm{EC}_{\mathrm{b}}=\theta \mathrm{EC}_{\mathrm{w}} \tau_{e}(\theta)$

Given that $\tau_{e}(\theta)=\tau_{d}(\theta)$ (Ghanbarian et al. 2013), the relationship between the relative soil electrical conductivity, $\mathrm{EC}_{\mathrm{r}}$ $\left(=\mathrm{EC}_{\mathrm{b}} / \mathrm{EC}_{\mathrm{w}}\right)$, and $D_{r}$ at high $\theta$ can be expressed as follows:

$\frac{\mathrm{EC}_{r}}{\theta}=\tau_{e}(\theta)=\tau_{d}(\theta)=D_{r}=k \theta^{n}$

where $n$ ranges from 1 to 2 .

At low $\theta$, where the percolation model cannot be applied, the relationship between $\mathrm{EC}_{\mathrm{r}}\left(=\mathrm{EC}_{\mathrm{b}} / \mathrm{EC}_{\mathrm{w}}\right)$ and $\mathrm{D}_{\mathrm{r}}$ can also be expressed by Eq. (8) under the assumption that $\alpha$ in Eq. (2) and $\beta$ in Eq. (7) are equal, but $n$ in Eq. (8) is approximately 4 .

\subsection{Four-Electrode Sensor Structure}

$\mathrm{EC}_{\mathrm{b}}$ was measured using a four-electrode sensor (Inoue and Shiozawa 1994; Rhoades and Ingvalson 1971). Four stainless-steel rods were inserted in parallel into an acrylic column of height $50 \mathrm{~mm}$ and inner diameter $50 \mathrm{~mm}$ (Fig. 1). The two outer stainless-steel rods acted as current feed $(i)$ electrodes, whereas the other two inner rods were used to measure voltage $\left(V_{2}\right)$. The two outer rods were connected to the resistance $(r)$.

The ratio of the electric current in the outer rods to the electric potential difference of the inner rods $\left(i / V_{2}\right)$ was proportional to $\mathrm{EC}_{\mathrm{b}}$, as shown in the following equation:

$\mathrm{EC}_{b}=G_{c} \frac{i}{V_{2}}=G_{c} \frac{\left(V_{1} / V_{2}\right)}{r}$

where $G_{c}$ is the sensor constant. $V_{1}$ is the voltage of resistance, $r\left(V_{1}=i r\right)$.

The ratio of $V_{1}$ to $V_{2}\left(V_{1} / V_{2}\right)$ was measured using a data logger (model 21X, Campbell Scientific Instruments). A $1-\mathrm{kHz}$ square wave was used as the $\mathrm{AC}$ voltage, whereas 100 and $3 \mathrm{k} \Omega$ resistance values were used at lower and higher $\theta$ values, respectively.

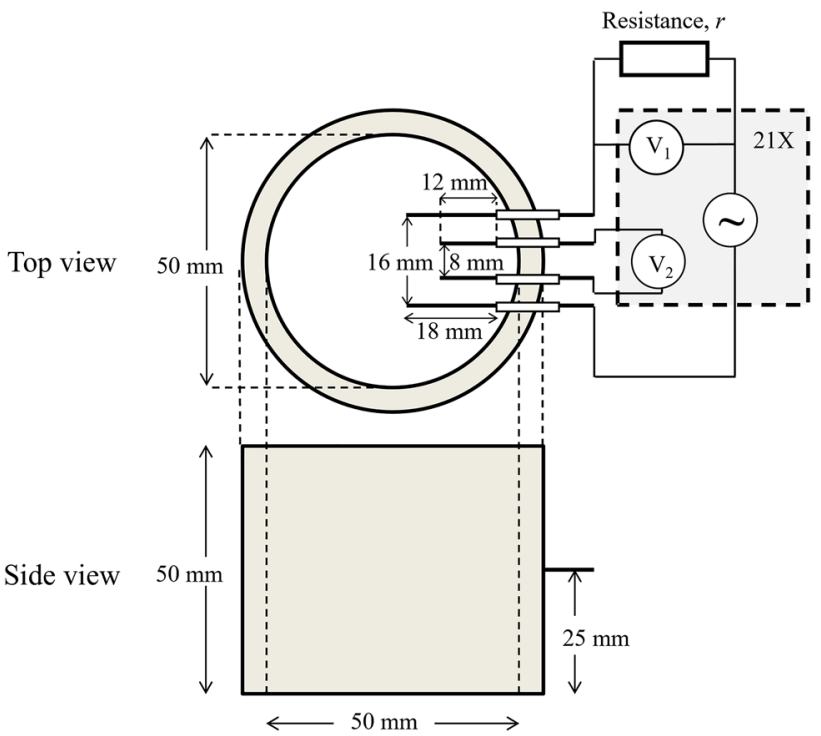

Fig. 1 Schematic diagram of the four-electrode sensor (Inoue and Shiozawa, 1994)

A sensor constant $G_{c}$ was calculated by measuring the electrical conductivity of $1.0 \mathrm{~mol} / \mathrm{L} \mathrm{NaCl}$ solution using an electroconductivity meter (MPC227 Dual Purpose Conductivity/PH/T Meter: Meter Toledo International, Inc.) as well as its $V_{1}$ to $V_{2}$ ratio at $25^{\circ} \mathrm{C}$ using the above-described fourelectrode sensor.

\subsection{Measurement of Electrical Conductivity of the Soil Samples}

Shonai dune sand (i.e., sandy soil with low clay content) obtained from the Shonai Sand Dunes in Yamagata Prefecture, Japan, as in Mehta et al. (1995) and Miyasaka et al. (2014), was used in the experiment (Table 1).

As $\mathrm{EC}_{\mathrm{b}}$ with very low water content hardly conducts electricity, high-concentration solution should be used for measurement. Inoue and Shiozawa (1994) investigated the relationship between $\mathrm{EC}_{\mathrm{b}}$ and $\mathrm{EC}_{\mathrm{w}}$ under the constant $\theta$ using clay and saltremoved sand and reported that the relationship between $\mathrm{EC}_{\mathrm{b}}$ and $\mathrm{EC}_{\mathrm{w}}$ can expressed by a linear equation at soil solution concentrations between 0.05 and $1 \mathrm{~mol} / \mathrm{L}$. Therefore, in this study, the sand was oven-dried, divided into seven equal parts, and placed in double-layered plastic bags, and subsequently, a predetermined amount of $1.0 \mathrm{~mol} / \mathrm{L} \mathrm{NaCl}$ solutions was added to each bag. After the sands were mixed, they were left undisturbed for more than $24 \mathrm{~h}$ to equilibrate. The sands were then uniformly packed into the column comprising the four-electrode sensor so that the soil bulk density was approximately $1.36 \mathrm{~g} / \mathrm{cm}^{3}$ (Fig. 1). The sensor was placed in a chamber at $25^{\circ} \mathrm{C}$. After the central temperature of the soil samples reached $25^{\circ} \mathrm{C}$, the $V_{1} / V_{2}$ ratio was measured at 1-min intervals for at least $15 \mathrm{~min}$, and the average value was obtained. After the measurement, the sand in 
the sensor was put back into the double-layered plastic bag. The same process was then repeated two more times, for a total of three measurements of the $V_{1} / V_{2}$ ratio.

Next, soil $\theta$ in the sensor was measured using a gravimetric method with oven drying. This method involves weighing the moist sand in the column, oven-drying it at $105^{\circ} \mathrm{C}$ for $24-48 \mathrm{~h}$, reweighing, and then calculating the mass of water lost as a percentage of the mass of the dried soil as follows:

$w_{c}=\frac{M_{w}-M_{d}}{M_{d}}$

where $w_{c}$ is the soil water content $(\mathrm{g} / \mathrm{g}), M_{w}$ is the mass of moist soil (g), and $M_{d}$ is the mass of the dried soil ( $\mathrm{g}$ ).

The volumetric water content, $\theta$, was calculated by dividing the mass of water lost in the column (i.e., $M_{\mathrm{w}}-M_{\mathrm{d}}$ ) by the volume of the column (Fig. 1, height, $50 \mathrm{~mm}$; inner diameter, $50 \mathrm{~mm}$ ).

The $\theta$ values of the soil samples were approximately 0.025 , $0.032,0.042,0.050,0.066,0.080$, and $0.270 \mathrm{~cm}^{3} / \mathrm{cm}^{3}$.

\subsection{Calculation of the Solute Diffusion Coefficient in Soil}

$\mathrm{EC}_{\mathrm{b}}$ was calculated to substitute the measured $V_{1} / V_{2}$ ratio of the soil samples as well as the resistance $(r)$ and sensor constant $\left(G_{w}\right)$ in Eq. (9). Similarly, the electrical conductivity of $0.1 \mathrm{~mol} / \mathrm{L} \mathrm{NaCl}$ solution at $25^{\circ} \mathrm{C}$ was calculated based on the $V_{1} / V_{2}$ ratio of the solution analyzed with the four-electrode sensor instead of the measured $V_{1} / V_{2}$ ratio of the soil samples.

\section{Results and Discussion}

The relationships between $D_{r}\left(=\mathrm{EC}_{\mathrm{r}} / \theta\right)$ and $\theta$ measured by the indirect method are illustrated in Fig. 2. The breakpoint existed at $\theta_{b r}=0.039 \mathrm{~cm}^{3} / \mathrm{cm}^{3}$, and the $n$ values in Eq. (8) were 0.9 at $\theta \geq 0.039$ and 5.9 at $\theta<0.039$. The relationships between $D_{r}$ and $\theta$ measured directly by Miyasaka et al. (2014) are illustrated in Fig. 3. The breakpoint existed at $\theta_{b r}=0.037 \mathrm{~cm}^{3} / \mathrm{cm}^{3}$, and the $n$ values in Eq. (4) were 0.7 at $\theta \geq 0.037$ and 3.8 at $\theta<0.037$. Although the breakpoints slightly differed between the direct method and soil electrical conductivity method and the values of $n$ at $\theta \geq \theta_{b r}$ and $\theta<\theta_{b r}$ also slightly differed, we found that the measurement of soil electrical conductivity could indicate the existence of the breakpoint. The relationship between $D_{r}$ directly measured by Miyasaka et al. (2014) and $D_{r}$ calculated by substituting the value of $\theta$ measured using the direct method described by Miyasaka et al. (2014) into the equation of $D_{r}-\theta$ derived from the $\mathrm{EC}_{\mathrm{b}}$ measurement method is shown in Fig. 4. The dotted line in Fig. 4 shows $D_{r}(=0.067)$ at the breakpoint $\left(\theta_{\mathrm{br}}=0.039\right)$. Although the values of $D_{\mathrm{r}}$ measured using the direct method (Miyasaka et al. 2014) and calculated from the equation for the measurement of $\mathrm{EC}_{\mathrm{b}}$ were different around the breakpoint, the overall correlation coefficient was 0.950 , indicating a markedly strong correlation.

Bezzar and Ghomari (2013) and Garrouch et al. (2001) reported that it was possible to estimate the solute diffusion coefficient by measuring electrical conductivity of saturated soil water using sand bentonite clay mixture and sandstone rock, respectively. Our findings also demonstrated that the indirect method can be used to measure $D_{r}$ in soils with high $\theta$ (where the percolation model can be applied) as well as low $\theta$ (where the percolation model cannot be applied).

Hamamoto et al. (2009), Olesen et al. (1999), Mojid et al. (2007), and Porter et al. (1960) measured $f$ in various soils with low $\theta$ and reported that the relationship between $f$ and $\theta$ is expressed by a linear function. In contrast, the results reported by Rowell et al. (1967), who measured $f$ at extremely low soil at low $\theta$, could not be approximated by a linear function and could be approximated by Eq. (4), as shown in the present study; the value of $n$ in Eq. (4) was 2.2 and 5.6 in soils with high and low $\theta$, respectively. In the studies conducted by Mehta et al. (1995), and Miyasaka et al. (2014), the value of $n$ in Eq. (4) ranged from 1 to 2 when the value of $D_{r}$ was greater than 0.1 ; the value of $n$ was approximately 4 when the value of $D_{r}$ was less than 0.1 . However, in the results reported by Rowell et al. (1967), the value of $n$ differed depending on whether the value of $D_{r}(=f)$ was larger or smaller than 0.01 . There is a possibility that the value of $D_{r}(=f)$ measured by Hamamoto et al. (2009), Olesen et al. (1999), Mojid et al. (2007), and Porter et al. (1960) cannot be approximated only by the linear function at extremely low soil $\theta$. Therefore, the behavior of $D_{r}$ at extremely low soil $\theta$ could be clarified in more detail using the indirect method (Fig. 5).

Although the dune sand used in this study was almost clayfree, the electrical conductivity of the surface of clay particles cannot be ignored when soil containing a large amount of clay is used (Mojid et al. 2007). Therefore, when the solute diffusion coefficient in the soil is estimated based on $\mathrm{EC}_{\mathrm{b}}$ measured at low soil $\theta$, the coefficient may be overestimated. Thus, this effect needs to be eliminated.

Table 1 Physical properties of the soil samples used in the experiments conducted by Mehta et al. (1995)

\begin{tabular}{|c|c|c|c|c|c|c|}
\hline \multirow[t]{2}{*}{ Soil } & \multicolumn{3}{|c|}{ Particle size distribution [\% contribution to total] } & \multirow{2}{*}{$\begin{array}{l}\text { Saturated water } \\
\text { content }\left[\mathrm{cm}^{3} / \mathrm{cm}^{3}\right]\end{array}$} & \multirow{2}{*}{$\begin{array}{l}\text { Saturated hydraulic } \\
\text { conductivity }[\mathrm{cm} / \mathrm{s}]\end{array}$} & \multirow{2}{*}{$\begin{array}{l}\text { Specific surface } \\
\text { area }\left[\mathrm{m}^{2} / \mathrm{g}\right]\end{array}$} \\
\hline & Sand & Silt & Clay & & & \\
\hline Shonai dune sand & 93.3 & 1.0 & 5.7 & 0.43 & $1.09 \times 10^{-2}$ & 22.1 \\
\hline
\end{tabular}


Fig. 2 Relationship between relative soil electrical conductivity/volumetric water content, $\mathrm{EC}_{\mathrm{r}} / \theta$, which is equal to the relative diffusion coefficient and volumetric water content, $\theta$, on a (a) $\log -\log$ scale and (b) linear scale (a)

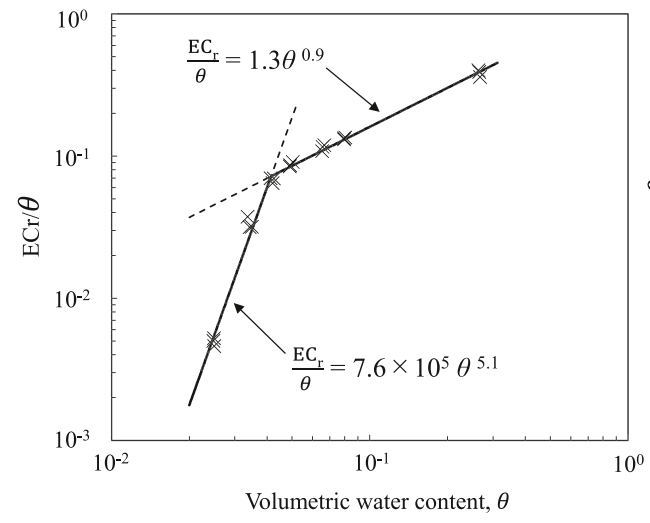

(b)

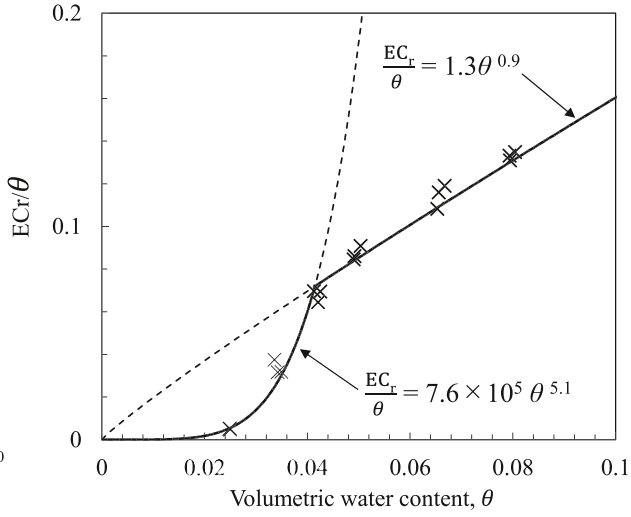

Fig. 3 Relationship between directly measured relative diffusion coefficients, $D_{r}$, and volumetric water content, $\theta$, (Miyasaka et al. 2014) on a (a) $\log -\log$ scale and (b) linear scale
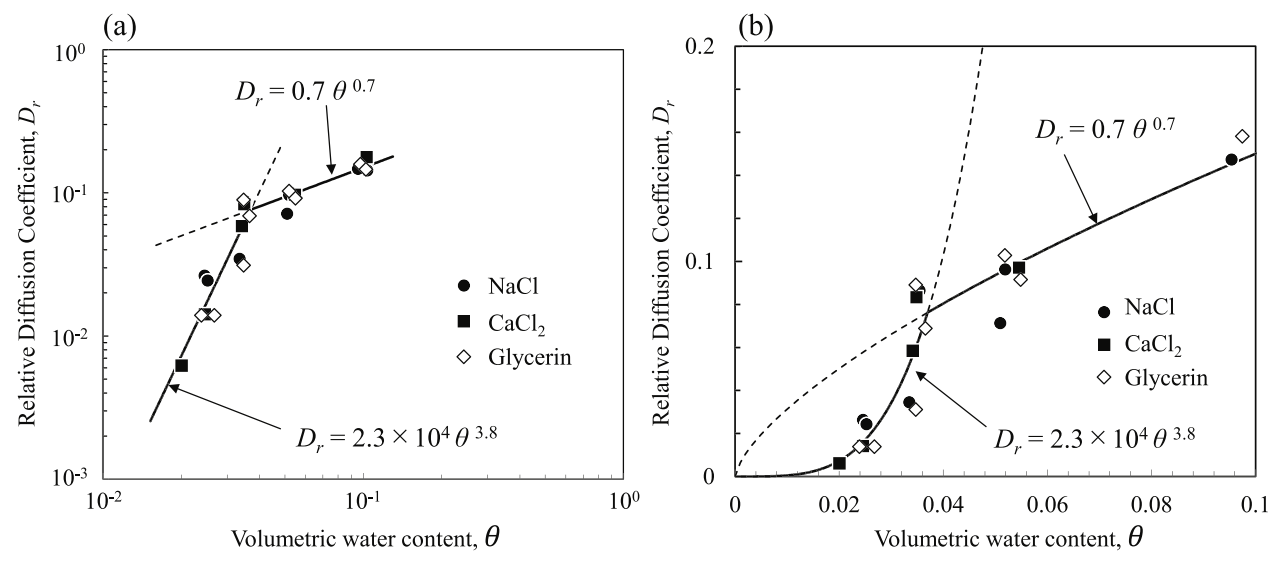

\section{Conclusion}

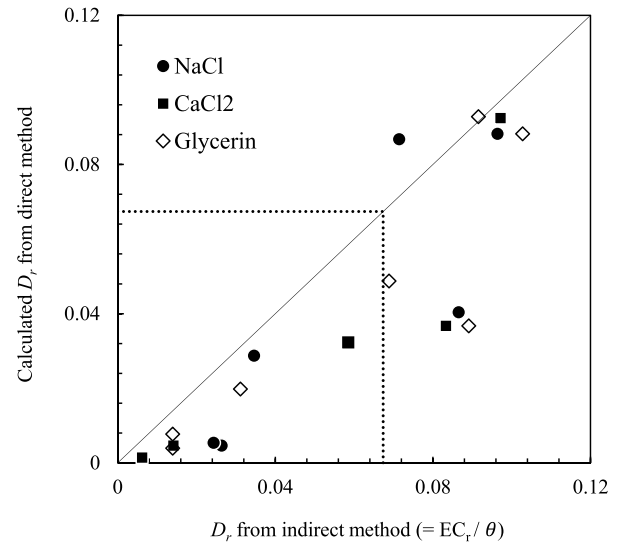

Fig. 4 Relationship between relative soil electrical conductivity/volumetric water content, $\mathrm{EC}_{\mathrm{r}} / \theta$, which is equal to the relative diffusion coefficient and $D_{r}$ calculated from the relational expression between $D_{r}$ and $\theta$ derived from the direct method (Miyasaka et al. 2014)
Some studies have reported the existence of a breakpoint $\left(\theta_{b r}\right)$ in the relationship between $\theta$ and $D_{r}$ at low $\theta$, and that the value of $n$ becomes approximately 4 when $\theta<\theta_{b r}$. This change in the $n$ value can be attributed to various mechanisms, including drastic changes in the geometrical distribution of pore liquid water caused by dehydration.

The transient-state method is typically used for measuring $D_{r}$. However, it requires considerable time to render sufficient data at low $\theta$, so few studies have measured $D_{r}$ at $\theta<\theta_{b r}$, and the relationship between $D_{r}$ and $\theta$ at $\theta<\theta_{b r}$ has not been adequately discussed. An indirect method for measuring $D_{r}$ is to determine the ECs. However, previous studies have not confirmed if this method is applicable at $\theta<\theta_{b r}$. Therefore, we calculated the solute diffusion coefficient in soil based on ECs measurements of high- and low- $\theta$ sand, wherein the presence of $\theta_{b r}$ was confirmed. The results showed that the relationship between $D_{r}$ and $\theta$ calculated based on ECs was almost the same as that measured using the transient state method, and $D_{r}$ can be calculated from ECs even at $\theta<\theta_{b r}$. 

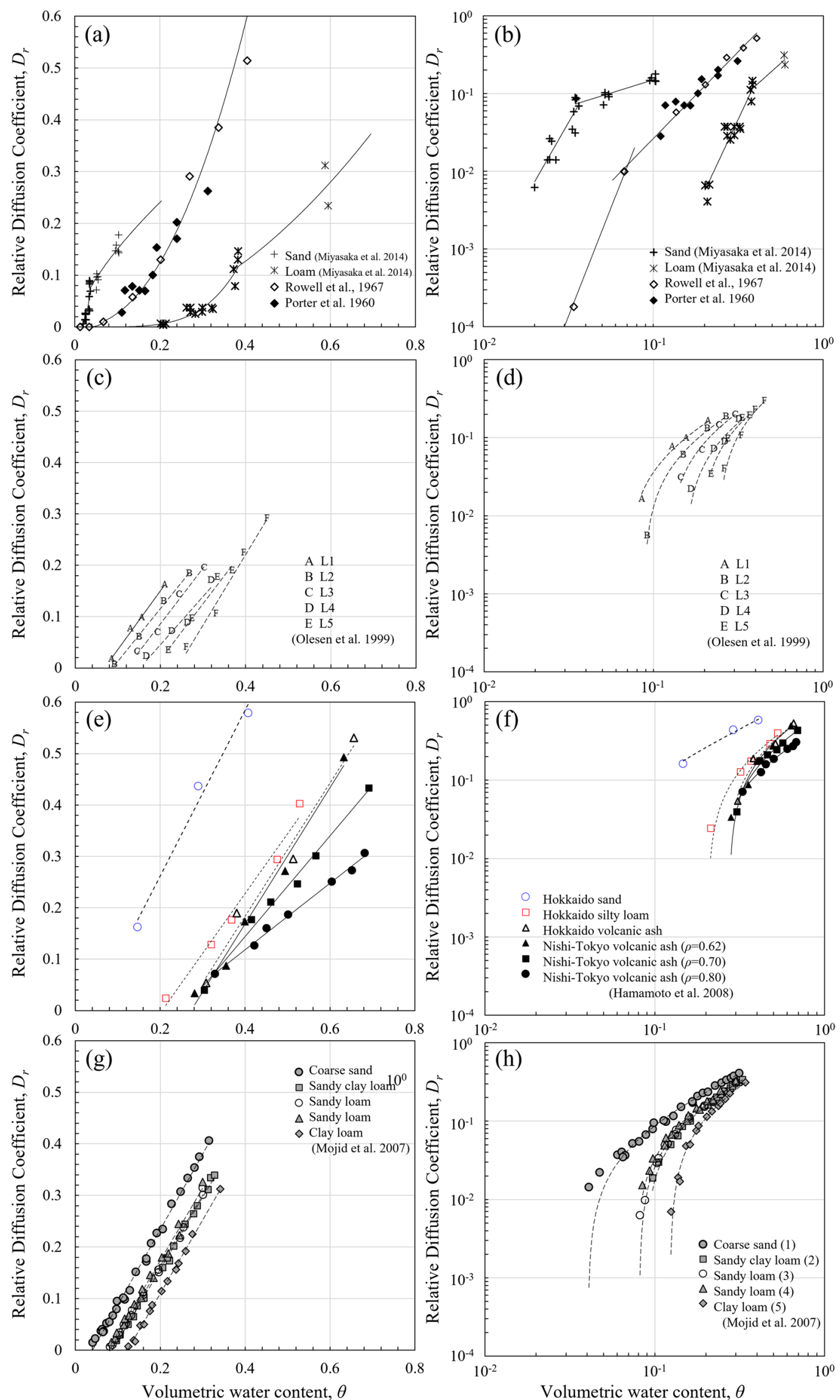
४Fig. 5 Compilation of literature on relative diffusion coefficient, $D_{r}$ (=impedance factor, $f$ ), as a function of volumetric water content. The figures on the left ((a), (c), (e), and (g)) are on log-log scale, whereas the figures on the right ((b), (d), (f), and (h)) are on a linear scale. These data are obtained either from the tabulation or digitization of figures published in the cited studies

Author contribution Conceptualization: K.M. and S.S.; data curation: K.M.; investigation: K.M.; methodology: K.M. and S.S.; project administration: K.M.; resources: S.S.; supervision: S.S.; visualization: K.M.; writing—original draft preparation: K.M.; writing—review and editing: K.M. All authors have read and agreed to the published version of the manuscript.

Funding This work was financially supported by Grant-in-Aid for Research Activity Start-up (No. 19K21163).

Data Availability The data can be made available upon request.

Code Availability Not applicable.

\section{Declarations}

Competing interests The authors declare no competing interests.

Open Access This article is licensed under a Creative Commons Attribution 4.0 International License, which permits use, sharing, adaptation, distribution and reproduction in any medium or format, as long as you give appropriate credit to the original author(s) and the source, provide a link to the Creative Commons licence, and indicate if changes were made. The images or other third party material in this article are included in the article's Creative Commons licence, unless indicated otherwise in a credit line to the material. If material is not included in the article's Creative Commons licence and your intended use is not permitted by statutory regulation or exceeds the permitted use, you will need to obtain permission directly from the copyright holder. To view a copy of this licence, visit http://creativeco mmons.org/licenses/by/4.0/.

\section{References}

Abderrahmene M, Abdelillah B, Fouad G (2017) Electrical prediction of tortuosity in porous media. Energy Procedia 139:718-724. https://doi.org/10.1016/j.egypro.2017.11.277

Barraclough PB, Tinker PB (1981) The determination of ionic diffusion coefficients in field soils. I. Diffusion coefficients in sieved soils in relation to water content and bulk density. J Soil Sci 32:225-236. https://doi.org/10.1111/j.1365-2389.1981.tb01702.x

Bezzar A, Ghomari F (2013) Monitoring of pollutant diffusion into clay liners by electrical methods. Transp Porous Media 97:147-159. https://doi.org/10.1007/s11242-012-0115-9

Conca JL, Wright J (1990) Diffusion-coefficients in gravel under unsaturated conditions. Water Resour Res 26:1055-1066. https:// doi.org/10.1029/WR026i005p01055

Conca JL, Wright J (1992) Diffusion and Flow in gravel, soil, and whole rock. Applied Hydrogeology 1:5-24. https://doi.org/10.1007/PL00010963

Ewing RP, Horton R (2003) Scaling in diffusive transport. In: Pachepsky $\mathrm{Y}$ et al (eds) Scaling methods in soil physics. CRC Press, Boca Raton, FL, pp 49-61

Garrouch AA, Liaqat A, Qasem F (2001) Using diffusion and electrical measurements to assess tortuosity of porous media. Ind Eng Chem Res 40:4363-4369. https://doi.org/10.1021/ie010070u
Ghanbarian B, Hunt AG, Ewing RP, Sahimi M (2013) Tortuosity in Porous Media: A Critical Review. Soil Sci Soc Am J 77:14611477. https://doi.org/10.2136/sssaj2012.0435

Hamamoto S, Perera MSA, Resurreccion A, Kawamoto K, Hasegawa S, Komatsu T, Moldrup P (2009) The solute diffusion coefficient in variably compacted, unsaturated volcanic ash Soils. Vadose Zone J 8:942-952. https://doi.org/10.2136/vzj2008.0184

Hunt AG, Ewing RP (2003) On the vanishing of solute diffusion in porous media at a threshold moisture content. Soil Sci Soc Am J 67:1701-1702. https://doi.org/10.2136/sssaj2003.1701

Inoue M, Shiozawa S (1994) Measurement of electrical conductivity in soil columns by the four-electrode method and its application. Soil Phys. Cond Plant Growth, Jpn 70:23-28

Mehta BK, Shiozawa S, Nakano M (1995) Measurement of molecular diffusion of salt in unsaturated soils. Soil Sci 159:115-121. https:// doi.org/10.1097/00010694-199502000-00006

Miyasaka K, Shiozawa S, Nishida K, Yoshida S (2014) Solute electrical charge effects on molecular diffusion coefficients in unsaturated soils. Soil Sci Soc Am J 78:1852-1858. https:// doi.org/10.2136/sssaj2014.05.0201

Mojid MA, Rose DA, Wyseure GCL (2007) A model incorporating the diffuse double layer to predict the electrical conductivity of bulk soil. Eur J Soil Science 58:560-572. https://doi.org/10.1111/j. 1365-2389.2006.00831.X

Olesen T, Moldrup P, Gamst J (1999) Solute diffusion and adsorption in six soils along a soil texture gradient. Soil Sci Soc Am J 63:519-524. https://doi.org/10.2136/sssaj1999.03615995006300030014x

Olesen T, Moldrup P, Henriksen K, Petersen LW (1996) Modeling diffusion and reaction in soils: IV. New models for predicting ion diffusivity. Soil Sci 161:633-645. https://doi.org/10.1097/00010694-199610000-00001

Olsen SR, Kemper WD, Van Schaik JC (1965) Self-diffusion coefficients of phosphorus in soil measured by transient and steady-state methods. Soil Sci Soc Am J 29:154-158. https://doi.org/10.2136/ sssaj1965.03615995002900020014x

Papendick RI, Campbell GS (1981) Theory and measurement of water potential. In: Parr JF, Gardner WR, Elliott LF (eds), Water Potential Relations in Soil Microbiology, Soil Sci Soc Am J, Medison 1-22. https://doi.org/10.2136/sssaspecpub9.c1

Porter LK, Kemper WD, Jackson RD, Stewart BA (1960) Chloride diffusion in soils as influenced by moisture content. Soil Sci Soc Am J 24:460 463. https://doi.org/10.2136/sssaj1960.03615995002400060014x

Rhoades JD, Ingvalson RD (1971) Determining salinity in field soils with soil resistance measurements. Soil Sci Soc Am J 35:54-60. https://doi.org/10.2136/sssaj1971.03615995003500010020x

Rhoades JD, Raats PAC, Prather RJ (1976) Effects of liquid-phase electrical conductivity, water content, and surface conductivity on bulk soil electrical conducitivty. Soil Sci Soc Am J 40:651-655. https://doi.org/10.2136/sssaj1976.03615995004000050017x

Rowell DL, Martin MW, Nye PH (1967) The measurement and mechanism of ion diffusion in soils III. The effect of moisture content and soil-solution concentration of the self-diffusion of ions in soils. J Soil Sci 18:204-221. https://doi.org/10.1111/j.1365-2389.1967.tb01501.x

So HB, Nye PH (1989) The effect of bulk density, water content and soil type on the diffusion of chloride in soil. J Soil Sci 40:743749. https://doi.org/10.1111/j.1365-2389.1989.tb01314.x

Tokunaga TK, Finsterle S, Kim Y, Wan J, Lanzirotti A, Newvillem M (2017) Ion diffusion within water films in unsaturated porous media. Environ Sci Technol 51:4338-4346. https://doi.org/10.1021/acs.est.6b05891

Yang R, Lemarchand E, Fen-Chong T (2016) A micromechanics model for solute diffusion coefficient in unsaturated granular materials. Trans Porous Med 111:347-368. https://doi.org/10.1007/s11242-015-0597-3

Publisher's Note Springer Nature remains neutral with regard to jurisdictional claims in published maps and institutional affiliations. 